\title{
AN ARGUMENT FOR INFRASTRUCTURE SYSTEM STEWARDSHIP: A NEW ZEALAND TRANSPORTATION CASE STUDY IN BENEFIT MANAGEMENT
}

\author{
C. BLOM \& P. GUTHRIE \\ Department of Engineering, Cambridge University, Cambridge, UK
}

\begin{abstract}
Benefits are intrinsic to infrastructure and the public sector, yet these remain a problem for many infrastructure sectors (including transportation), organizations and countries. Much of the focus upon benefit management targets project delivery; by contrast, this study considers system-level benefit management using a transportation case study from New Zealand. In so doing, it investigates why the matter of benefits might be so problematic, and in what way this might affect the integration of projects into the extant system.

The research shows system-level coordination and integration are being lost within the "tactical strategy' of programmes and initiatives. In turn, this is creating a 'red queen'-like busyness without a real understanding of whether anything has been achieved relative to the intended or necessary outcomes being sought. System stewardship has therefore been advanced as an appropriate response to systemlevel complexity and a potential enabler of strategic agility and adaptive capacity.

Keywords: benefit realization, integration, stewardship, system thinking, transportation.
\end{abstract}

\section{INTRODUCTION}

Benefits are intrinsic to infrastructure and the public sector. However, benefit management still remains an area of concern to the wider infrastructure industry. For example, Blom and Guthrie [1] found benefit management to be a commonly shared issue for a wide range of practitioners across infrastructure sectors (including transportation), organizations and countries. They observe that whilst there is an:

overarching issue [that] relates to the long-term performance of infrastructure and thence the alignment of infrastructure governance and operations, this really amounts to how organisational structure and business practice define or shape engineering decision-making and infrastructure outcomes. Benefit management...processes probe and transect this space and have been highlighted as areas for further investigation .

This article advances that earlier research by investigating system-level benefit management in further detail. It does so by using New Zealand's publically owned land transport as the subject of the research, and focuses on Auckland Transport, the entity responsible for transportation management (excepting the state highway network), in Auckland, New Zealand's largest region. Auckland Transport was formed in 2010 from a restructuring of local and regional governments and has planned a capital investment programme of NZ $\$ 60$ billion (equivalent to approx. €38.6 billion) over the next three decades (Auckland Transport [2]).

This research assesses governance and strategic practice together with how this interrelates with project-level benefit management. It does this by assessing strategic connectivity, benefit visibility at board-level, and project-level benefit management. In so doing, the research investigates why the matter of benefits might be so problematic, and in what way this might affect the integration of projects into the wider (extant) transportation system. However, this article does not purport to calculate the benefits of a project or of the system. Rather, the 
approach provides a methodological tool for assessing the effectiveness and 'fitness' of processes that are being deployed to calculate, manage and deliver the benefits of transportation and other infrastructure systems.

\section{BENEFIT MANAGEMENT AND TRANSPORTATION}

According to Breese [3] and Tillmann et al. [4], benefit realization has relatively recently emerged as a mainstream management paradigm out of the technology sector. A number of frameworks and tools have since been advanced to assist benefit management. Some of these have been aimed specifically at the public sector and have subsequently been integrated into project and programme management policy and practice (e.g. May et al. [5]).

New Zealand, which is the focus of this case study, has followed suit by adopting the United Kingdom's Gateway review process (State Services Commission [6]). Benefit management, as an identifiable discourse, with its associated milestone hold points, should therefore be entering the language of the public sector. Within New Zealand's public transportation infrastructure providers, such as the local government entity studied here, this should - in theory at least - be less of a watershed because:

- benefit cost ratios (BCRs) are a prevalent investment decision-making tool (e.g. NZTA [7]), and in New Zealand, transport investment now also includes assessment against strategic fit (NZTA [8]); and

- projects are often required to demonstrate that 'the work and designation are reasonably necessary for achieving the objectives of the requiring authority...' (Schedule 4, and s168A(3)(c); 'Resource Management Act,' [9]; emphasis added).

Notwithstanding the point here that benefits are already an embedded consideration within the transportation sector, it is somewhat surprising that benefit realization would, or could, ever be viewed as an emergent paradigm for any infrastructure sector at all. Yet, this would appear to be the case. The definition of infrastructure ('Oxford English Dictionary (online version)' [10]) inherently presupposes any outcome to be positive and therefore that projects deliver or renew benefits, and operations service, maintain or enhance those benefits over time; an infrastructure benefit then is simply that which is for the good of, improves, or helps forward (Ibid.) that society or enterprise.

Of course none of this implies that benefit delivery has been, or currently is, exemplary. Moreover, some of the project-oriented frameworks may be problematic because transportation infrastructure exists as a system comprising an interwoven fabric of assets, projects, networks and services at varying stages of their life cycle, and:

- Projects and programmes are not always self-contained and may inherently rely on the delivery of other projects or services (sometimes between different departments or entities) to enable benefits to be realized (Blom \& Guthrie [11]);

- Project and programmes are predominantly delivered to effect change to (i.e. benefit) an existing infrastructure system. Once absorbed, benefits may no longer be able to be sufficiently differentiated or may be 'explained away' (Flyvbjerg et al. [12]);

- Transportation systems exist as a long-term continuum that can extend far beyond the initial design life of the hard assets (Quinet [13]); and therefore

- Strategy is formed incrementally through a non-linear and concurrent process of analysis, formulation and implementation (Thiry \& Deguire [14]). 
This suggests that whilst benefits might be expressed in terms of broad, societal (i.e. 'system-level') objectives, there is a need to move beyond the current project-oriented view that ultimately informs subsequent processes within project, programmes and the wider organization (Blom \& Guthrie [1]). However, changing focus can be challenging, especially when ongoing growth and economic prudence drive a demand for improved project management practices and rigour. Furthermore, adherence to a project perspective is often unhelpful (e.g. Lenfle \& Loch [15]).

Another emergent general management trend, the 'project based organisation' (e.g. Thiry $\&$ Deguire [14]) - arguably the status quo for many infrastructure organizations - will only serve to reinforce project-oriented practice. If an organization (and the infrastructure it manages) is, itself, viewed as a form of mega-project, then these problems might be similarly expected, even if expressed at different scales and time frames.

\section{METHODOLOGY}

This study transects the organization by completing a 'deep dive' across three levels of benefit management: how benefits are framed in strategy; how visible benefits are at board level; and what happens to benefits within projects. The research concerns itself with the ability to sustain strategic intent once a given project or programme has been decided upon, and its integration into both the wider organization and transportation systems. As such, the research focuses on the strategy to project interface and system-level benefit management.

Benefit framing was assessed by mapping the objectives and outcomes from key strategic documents. This entailed converting the suite of objectives and outcomes for each document into a 'subway map' then completing connections according to the linkages established by the documents themselves. Importantly, this provided a visual representation of the organization's strategic framework and enabled both relative connectivity and disconnects to be readily and systematically identified.

The strategic documents considered were the Auckland Plan (Auckland Council [16]), which provides the strategic direction for the region, and five subordinate Auckland Transport strategies: the Integrated Transport Programme (ITP; Auckland Transport [2]), Asset Management Plan (AMP; Auckland Transport [17]), Regional Land Transport Plan (RLTP; Auckland Transport [18]), Regional Public Transport Plan (RPTP; Auckland Transport [19]), and the Parking Strategy (Auckland Transport [20]). Performance measures were also mapped for the same documents plus measures from the two latest versions of Auckland Transport's Statement of Intent (SOI; Auckland Transport [21, 22]).

How long-term or system-level benefits were visible to the board was analysed from 765 board reports that spanned the organization's formation (November 2010) to December 2015. Finally, key project-level issues were identified from a review of 128 available project documents for one of Auckland Transport's flagship capital programmes; the Auckland-Manukau Eastern Transport Initiative (AMETI) is a major, multimodal programme aimed at improving strategic transport links in the east of Auckland. At approximately NZ\$1.16 (or approx. € 0.8) billion, AMETI was - at the time this research commenced - one of the largest transportation programmes under construction in the region. The final, project-level analysis was augmented by research observations, a site visit and:

- prior organizational studies;

- 59 multinational, industry-wide interviews (Blom \& Guthrie [1]); and

- seven study-specific interviews with either Auckland Transport or its advisers, and an interview with the office of the controller and auditor general. 


\section{STRATEGIC INTERRELATIONSHIPS}

According to Auckland Transport documents, there is a document hierarchy, so one would expect strategies to cascade out of the higher-order vision, objectives, policies and directives. However, this does not always occur (Fig. 1). Connections were either absent (e.g. Parking Strategy to ITP) or generalized (e.g. ITP to Auckland Plan). The overview of both the strategic framework and board documentation also highlighted the importance and complexity of organizational performance measures. Measures ranged from strategic indicators through to tactical levels of service; the difference between these was not always immediately apparent.

As a general observation, Auckland Transport's strategies are dominated by the hard infrastructure typology - through either asset management or capital development. Service-related strategies are largely absent or reduced to general satisfaction surveys within performance measures. The research also found that strategic frameworks can be undermined by factors such as the following:

- The relative timing of strategy development. In this instance the hierarchy appears to have been immediately compromised by the order in which documents were produced.

- The ability to manage change. This includes the iteration and review of strategy, and the ability to synchronize and align documents. The inability to follow 'threads' throughout the system exacerbates disconnects within the strategic framework.

- The promulgation of new strategic documents, strategies and measures.

- The ability to understand, connect and align all parts of the system; between documents, strategies, measures, and then between all three layers. This is more than a matter of complexity, but requires a purposeful documentation of explicit links so that meaning can

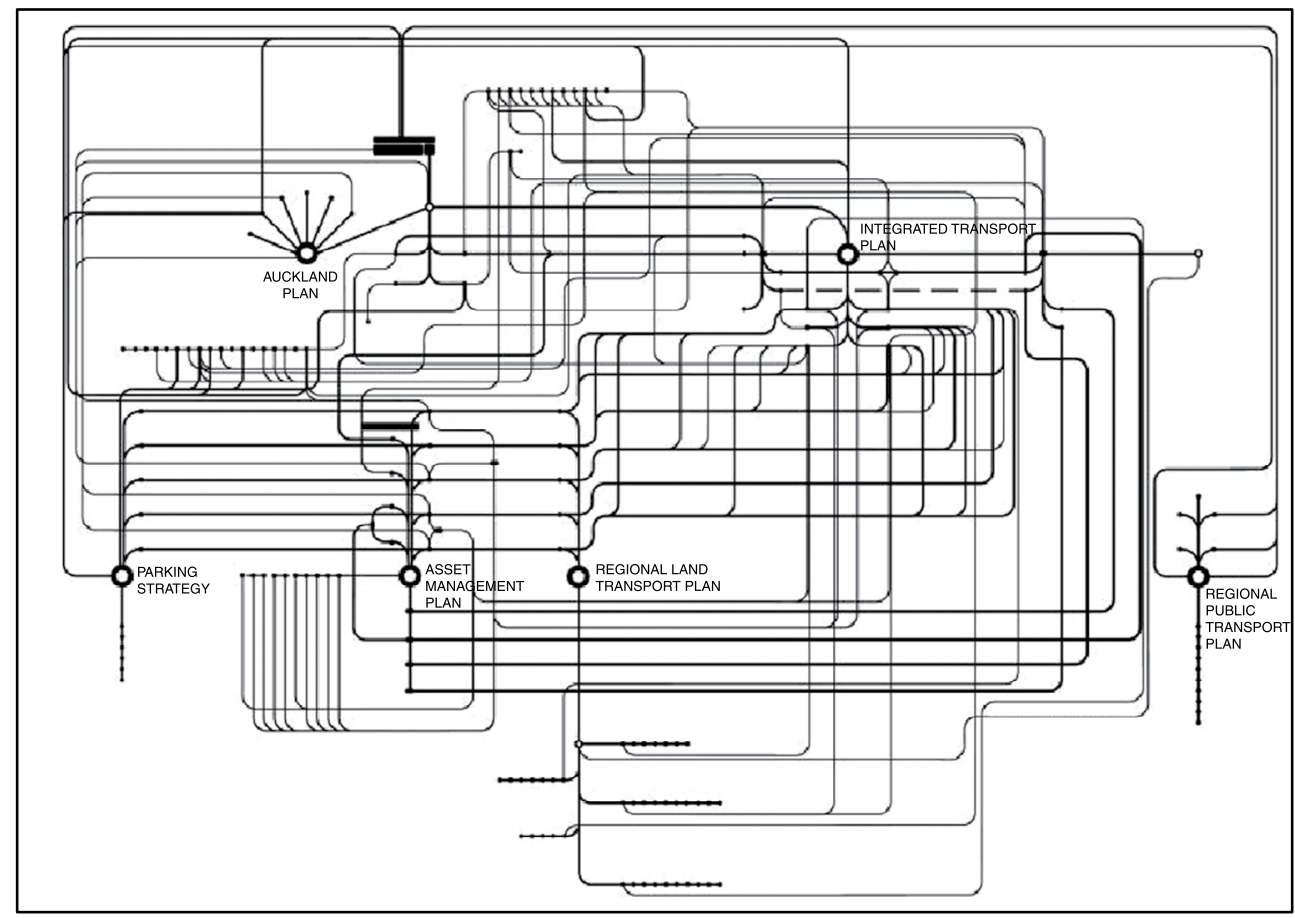

Figure 1: Overview schematic of strategic interrelationships (detail not shown). 
be communicated and connections understood. Connectivity is important for several key reasons:

- Whilst linkages might be inferred, these can be open to interpretation, whether between organizations, departments or by stakeholders. So something more than the application of 'common sense' is required for transparency and strategic direction.

- The more connected a strategy or measure, the greater the visibility within the organization; this relates to the matter of salience (Mitchell et al. [23]). Strategies or initiatives that become isolated are at risk of being omitted due to lack of visibility within the wider system.

- What is more, transparency would enable outcomes to be evaluated across multiple levels of the organization (recalling that performance measures do not measure or target everything), and enable organizational learning and (r)evolution.

- The complexity of the strategy and therefore the inability to clearly communicate requirements and how everything fits together (i.e. 'how do I contribute?').

These factors affect transparency, accountability, follow-through, and thence the ability to review, learn, adapt and evolve.

With the strategic framework having the potential to be compromised in this way, there is, in turn, an issue for the management of outcomes. In essence, there is nowhere for project-level benefits (within both operations and capital development) to tie into the strategic framework; there are simply too many disconnects. Subsequently, even with a stage-gate assessment of benefits, the contribution to the overarching system-level objectives may not be able to be ascertained or have much meaning.

\section{BENEFIT VISIBILITY}

Nadler and Tushman [24], amongst others, argue that goal attainment is one of the fundamental pillars of organizational performance. At face value, then, one would expect benefits to be highly visible within board documentation given the key role of governance "is to ensure that corporate management is continuously and effectively striving for above-average performance, taking into account risk" (Australian Independent Working Party into Corporate Governance, cited in Grant et al. [25]). Yet in the case study organization:

- benefit management is not highly visible at the board level;

- there is both a disconnect and a lack of transparency between strategic intent and the proposed benefits of projects or initiatives; and

- reported follow-through and feedback are virtually non-existent, or reported in a way that suggests the organization retains knowledge or enables organizational learning and adaptation.

It is apparent that since the first generation of strategies was released in 2012-2013, the organization and its board are aware of some of these issues and are trying to effect a culture change. There is, for example, a project audit framework (which includes benefit realization), and there are examples where benefits were being actively managed within parts of the organization. There has also, more recently, been a greater focus on operations and service delivery than was seen within strategic documents.

However, just as the strategy is dominated by the hard infrastructure typology, board documentation is dominated by features, which become little more than a list of actions and 
outputs in the absence of clearly established benefits and feedback loops (and is reinforced by the current form of the strategic documents). This 'red queen-like' busyness without a sense of progress (Carroll [26]) has been noted by Auckland Transport's shareholder (Auckland Council) and in the public's submissions to strategic plans. What is also not apparent from the available documentation is how the individual parts of the organization and network act upon each other and influence the benefits at the system level. This was particularly apparent in the way performance indicators were reported; there was no sense that the whole of the organization considered how their actions either benefited or adversely affected strategic goals. Finally, the documentation often relied on inference or superficial assessment in areas such as:

- strategy and performance indicators, projects or actions;

- project alignment with, or interpretation of, strategy; and

- the inherent 'goodness' of a project, action or technical process.

We expand last of these points by way of example.

Much of the material relating to capital development focused on the delivery of features, their cost and the programme of works. At face value this is, perhaps, reasonable; the project benefits and disbenefits will have been subject to a high level of scrutiny through the business case, and typically also some form of statutory approval process. However, there appear to be some issues with this and a sense that once approved, a project is inherently beneficial.

Moreover, the reporting of BCRs within board documents does not define the benefits in a way that would enable benefits to be managed or subsequently evaluated. This has an interface with the matter of consequential operating expenditure (consequential OPEX; Blom \& Guthrie [11]), as the benefits are reliant upon an assumed frequency of services. Budgets need to be set aside to enable benefits to be delivered over time, and the requirement to complete other actions to enable the core activity also need to be understood and provided for. Moreover, the BCR is an investment decision-making tool and does not:

- necessarily provide for long-term operational requirements (Ibid.) or cover all benefits; or

- provide any indication of whether the right benefits are being delivered, and what is being compromised (Damart \& Roy [27]).

This last point is particularly relevant to scope change decisions as simply reporting a change in the BCR gives no indication of whether the project will still deliver the outcomes that were either intended or required. In short, project initiation and other go/no-go decisionmaking, together with scope change, received very little coverage within board documentation. Any discussion that did occur was not specific enough for long-term benefits to be understood, managed or verified. This raises several significant questions:

- What is the basis being used to approve or vary projects (i.e. how do they connect to strategy, and how are they being expected to transform the current system)?

- How are benefits then being articulated to projects?

- How can projects be held accountable for benefits and outcomes?

- What is the purpose and benefit of a stage-gate benefit realization and management system in this context?

- What interventions delivered the expected benefits, what didn't work, and what could be improved next time?

- If not the board, then who is responsible for closing system strategic loop? 
The issues (as highlighted through the assessment of board-level benefit visibility) curtail the unbundling of benefits, transparency, and feedback, and thence knowledge retention, learning, and accountability. Consequently, project-level benefit management can only be one part of the solution and in itself is unlikely to result in improvements to the infrastructure outcomes being sought.

\section{PROJECT-LEVEL BENEFIT MANAGEMENT}

At the project level, it appears that this matter is as much about the benefit realization process, as it is about realizing that there are benefits (and disbenefits) to be managed, and that those benefits:

- are the primary focus for the project or programme;

- are externally focused;

- unfold in detail as the project advances;

- may still evolve and change over time;

- exist at multiple levels and respond to many functional (e.g. organizational department and technical discipline) needs; and

- have several dimensions that respond to customer need, beliefs, choice and aptitudes.

Stage-gate frameworks are therefore all well and good, but as Lenfle and Loch [15] point out, 'the performance track record of megaprojects is dismal, even though the basic ingredients of successful large project management are not new. Put simply, the trick is to combine uncertainty in dealing with the difficulties of long time horizons and non-standard technologies with stakeholder complexity'. It might be trite, but as the other analyses within this research have shown, it is necessary to add: whilst retaining focus on the intended, right, and/ or all benefits.

Whilst there are many challenges with the delivery of complex infrastructure projects and their benefits (e.g. Lenfle \& Loch [15]; OMEGA Centre [28]), those benefits are ultimately directed at a third, often amorphous, party - a community or society at large. Irrespective of any community consultation or collaboration, those stakeholders do not often have a strong voice within the organization itself. What is more, their organizational proxies - the operational divisions of an infrastructure organization - also do not seem to be actively involved to provide the voice of 'the client'.

It is also somewhat telling that in this instance, benefit management was delegated to the financial team, inherently aligning the benefit management process with the investment and funding decision. This may be necessary at one level; however, whilst benefits are assessed at the project level as part of investment and statutory decision-making processes, this is not necessarily addressing system-level outcomes. The benefits as assessed by a BCR might be useful in an ex post assessment and review of benefit delivery, but should not be assumed as the complete picture, as benefits need to be considered from multiple perspectives and through many levels. Whilst the BCR notionally provides for a wide range of benefits, these can be mired in the focus upon traffic modelling, or receive less attention because wider benefits may be less familiar/less quantifiable, or omitted/given cursory attention (e.g. because traffic-related benefits were deemed sufficient to get the project 'over the line').

Disbenefits too need to be managed and this is not necessarily the same as risk management or the weighing of the benefits versus the disbenefits of project options. Something more active is required. For example, in the New Zealand context, statutory processes are 
likely to stipulate requirements that avoid, remedy or mitigate adverse environmental effects. Consequently, other benefits may have a different focus and scale from those aimed at the system or strategic level.

Similarly, there is no process for managing 'deferred benefits', giving rise to a belief that certain benefits have been delivered or 'problems sorted'. Overcoming the inertia that this creates, let alone any funding shortfall, can be challenging (see Blom \& Guthrie [11]).

Finally there is the matter of the three ' $F$ 's': feedback, feed-forward and follow-through:

- Feedback: There is currently no mechanism to provide feedback to the project team even though benefits and organizational reputation were two of the attributes upon which project success would be judged; Doz and Kosonen [29] describe this as strategic atrophy. Information and assumptions used to assess and approve the project are not reused (and so tested), and necessary benchmark or baseline information obtained to enable the necessary comparisons to be made. It was felt in some quarters that there would be a reluctance to actually complete such an assessment as the project/organization would be found wanting.

Some ex post feedback was sought from the community surrounding the project; however, this appeared to extend to generic satisfaction surveys. One problem with customer satisfaction surveys is that they are really only asking about the customer's satisfaction with the asset. This is not the same as asking whether they are satisfied that it helps them with their lives (Blom \& Guthrie [30]). So, although the project was predicated on achieving a significant modal shift (Auckland Transport [31]), this does not appear to have been explored by, for example, asking the community whether they now believed that they could give up a car (and if so why/if not, why not?). Such a question, and change in focus, would have enabled ongoing learning and goal-seeking behaviour as advocated by the likes of Ackoff [32].

- Feed-forward: There is currently no mechanism for passing feedback on to strategy; to inform traffic models, patronage data, or other factors. Newig et al. [33] too highlight the need for learning at the level of network governance rather than at the actor level.

- Follow-through: Similarly, there is no process for capturing the multiple layers of benefits as they emerge within the project, and to follow the threads through both the organization and the life cycle. This needs to transcend organizational, functional, personal and other boundaries. The impacts of this were seen through the assessment of consequential OPEX as described in Blom and Guthrie [11].

\section{WIDER INDUSTRY RELEVANCE}

As described in Blom and Guthrie [1], benefit management was a key theme to arise in a series of multinational, cross-sector industry interviews. The wider industry views were assessed against the key themes to emerge from this study, but for brevity have not been included here. Whilst there are some contrary views, these tended to be in the category of 'could do better', or a 'work in progress', and in the minority. This research is, by its very nature, organization-specific in its detail (and not generalizable at this level), however, the commentary from the wider, international industry points to shared concerns and issues.

One of the interesting aspects to be commented on within the wider interviews related to the role of 'unrelated' organizational processes such as the personal performance and development measures stemming from human resources. This is broadly on the same continuum as the measures of success for project managers; however whilst a project manager might be an external provider, in-house performance measures can be somewhat more difficult to 
unpick and reorient. This thread was explored in more detail with a human resources specialist from the infrastructure sector. They acknowledged that linking career development to specific tasks in this way had created issues in the past, and whilst the practice was changing, still had some way to go. It would therefore appear that just as the consequential OPEX study recommended financial practice change to better enable long-term infrastructure outcomes, other support areas such as human resources also need adjustment to better align these to the public administration of infrastructure. This, of course, is not new (e.g. Box [34]; Metcalfe [35]), but given the observations from within industry, it is yet to be fully resolved (see also Doz \& Kosonen [29]).

\section{DISCUSSION}

Whilst there are a number of mechanisms available for managing benefits (whether as part of a specific benefit realization framework, or general asset or project management guidance) the dynamic, and non-linear nature of infrastructure as a system, means that these are unlikely to be sufficient on their own. This is because they target one part of the infrastructure life cycle, and this is reinforced by organizational structure and other decision boundaries.

What this study has shown is that benefits need to be understood and managed at a variety of levels that reflect organizational structure and function, customer need/system objectives, discipline and timescale (amongst others). Furthermore, whilst various tools may be useful in managing discrete packages or projects, they may actually reinforce system-level disconnects by suggesting a sufficiency rather than continuum of outcome and may do so from a singular perspective that may not necessarily capture or reconcile all requirements. As part of the wider programme that surrounds this research, Blom and Guthrie [1] found there to be four dimensions that affect how long-term infrastructure outcomes are understood:

- Needs: What is delivered and how it is delivered;

- Precepts: What customers believe or expect to be delivered;

- Choices: Whether the choices are appropriate, purposeful and compromises understood; and

- Aptitudes: Whether or not there is the ability to both proactively and reactively change.

These four dimensions emerged from the analysis of the board documentation and envelop matters that enrich benefit complexity, such as value delivery. Infrastructure outcomes and benefits also need to extend beyond merely society's interaction with assets (how it uses the physical infrastructure) to what the infrastructure enables (Blom \& Guthrie [30]). Consequently, infrastructure requires particular care to orient benefits towards the communities it is being designed to serve. In the transport sector, for example, the movement of things should not be conflated with the movement of people.

As a new organization, Auckland Transport has had the opportunity to re-establish strategy and reorient the organization towards benefit delivery. However, the focus on maintaining the delivery of projects has resulted in the misalignment of strategic documents in several areas, and strategies becoming tactical. The factors encountered contribute to benefits being neither highly visible nor transparent at the governance level of the organization. This in turn amplifies the absence of benefit management at the project level and the failure to feedback into strategy. Again, the industry-wide interviews suggest that Auckland Transport is not alone.

Whilst project-level benefit management is necessary, projects are the means through which the existing infrastructure system transforms. The day-to-day management of the 
infrastructure system rests within the operational realm; but this too needs to reorient to a systems perspective (Blom \& Guthrie [1]). For infrastructure management to better align with strategic intent, of vital importance is another level of benefit management aimed at the whole of the organization, the infrastructure system, and the progressive and continually evolving outcomes it is seeking to achieve. This is not simply a matter of applying existing tools and frameworks to the organization as a whole (but they may help).

Beyond this, it would appear that there would be merit in purposeful system stewardship (Fig. 2). Zimmerman and Sparrow [36] describe stewardship as 'a collective sense of ownership or accountability', and the concept is described by Senge [37] as a paradox akin to that of evolution: 'a process of "transformation through conservation"”.

The notion of system stewardship is not new - at least in New Zealand where it has cultural roots and has since been enshrined in the 'Resource Management Act' [9]. In the 1990s Dunning noted that public sector organizations were 'the only agent to have broad social system stewardship responsibilities' (cited in Doz \& Kosonen [29]). However, the concept seems only more recently to have been gaining traction, mainly within the healthcare sector (e.g. Alvarez-Rosete, et al. [38]). Whilst the need to integrate benefits at the system level might seem self-evident, this is not a concept that currently appears widely within the literature associated with the 'hard' infrastructure sectors. Moreover, industry-wide interviews suggest this is also not prevalent within practice. It is, however, supported by Hallsworth ([39]; as introduced by Nash), in the field of 'new economic thinking', who argues that system stewardship has the potential to 'significantly improve strategies for governing' (emphasis added). This is not proposed as another layer of bureaucracy, and key to this model is that:

- the organizations framework is operationally oriented towards the system and its longterm outcomes. This includes resolution of divergent commitments, objectives and resources (Doz \& Kosonen [29]), and the incremental development of strategy (Thiry \& Deguire [14]);

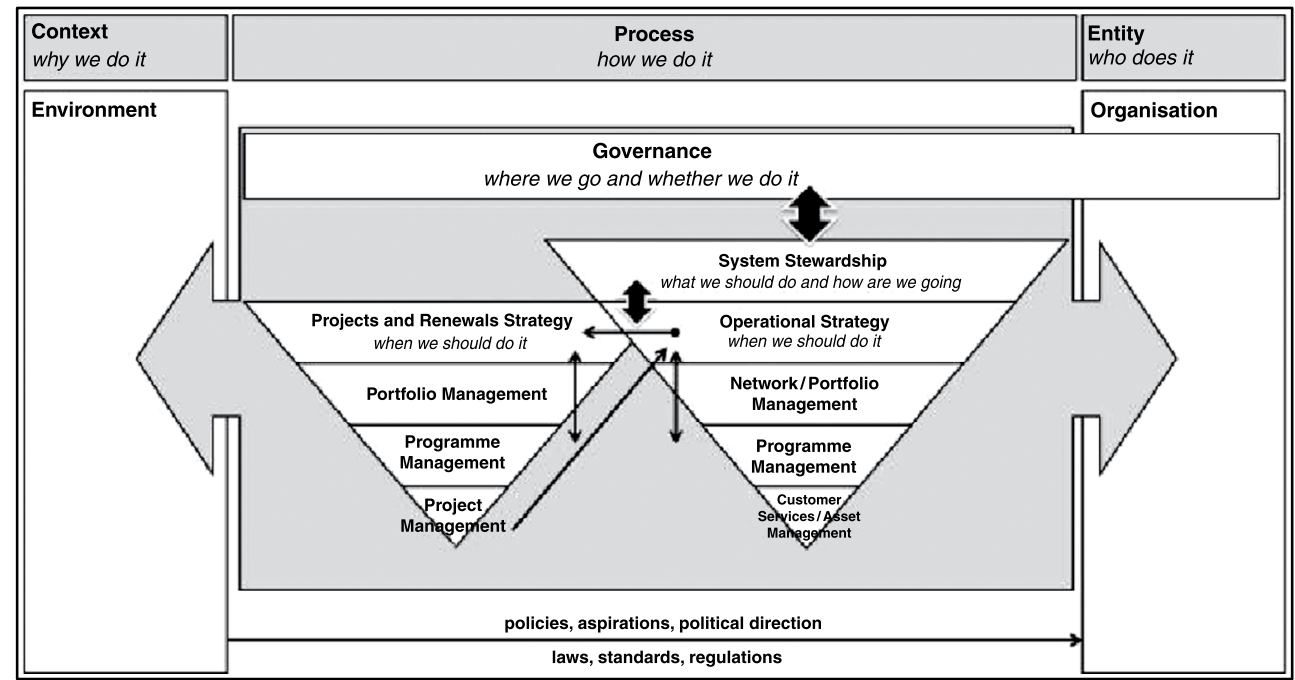

Figure 2: System stewardship framework. 
- system stewardship provides a strategic interface to governance by synthesizing feedback from operations and projects and feeding this forward to organizational strategy and governance-level decision-making;

- there is greater accountability within the system. Operations must define, and capital development must follow through on project outcomes and benefits; and

- operational divisions are oriented away from functional boundaries and focused upon integrated long-term service outcomes.

Without proactive and purposeful system stewardship, infrastructure benefits are unlikely to be fully realized over the long term. Moreover, the establishment of a system stewardship function provides an organizational mechanism to enable strategic agility and adaptive capacity, and to evoke the story telling necessary to augment the management of a complex adaptive system over time (e.g. Snowden [40]).

\section{CONCLUSIONS}

This research has explored benefit management across the strategy to project interface using three mechanisms, aimed at different aspects of this interface: the connectivity of the strategic framework, benefit visibility at board level and project-level benefit delivery. The study shows that whilst theoretical frameworks are likely to be useful, these are bounded approaches that do not necessarily assist the organization align the benefits with a strategic context that is dynamic, and which should be system focused and externally oriented. Moreover, the organization needs to actively anticipate feedback, feed-forward and follow-through from the tactical delivery of operations and capital development to enable any benefit management or realization 'scheme' to have any real meaning or traction.

It is clear from the research that system-level coordination and integration is being lost within the 'tactical strategy' of programmes and initiatives. As a consequence, this is creating a 'red queen'-like busyness without any real understanding of whether anything has been achieved relative to the intended or necessary outcomes being sought. The notion of system stewardship has therefore been advanced. Whilst this is not a new concept, it has only recently appeared within the health sector and still appears to be a novel concept within hard infrastructure. Moreover, it appears to be an appropriate response to system-level complexity and a potential enabler of strategic agility and adaptive capacity.

\section{ACKNOWLEDGEMENTS}

This case study would not have been possible without the assistance of Auckland Transport in providing access to both staff and data. We are also grateful to Auckland Transport and Anguillid Consulting Engineers and Scientists Ltd for funding the research.

\section{REFERENCES}

[1] Blom, C. \& Guthrie, P., Towards an Investigation of Long-Term Infrastructure Performance [online ahead of print]. Proceedings of the Institution of Civil Engineers Engineering Sustainability, 2016.

[2] Auckland Transport. 2012-2041 Integrated Transport Programme, Auckland: New Zealand, 2013.

[3] Breese, R., Benefits Realisation Management: Panacea or False Dawn? International Journal of Project Management, 30(3), pp. 341-351, 2012. DOI: 10.1016/j.ijproman. 2011.08.007. 
[4] Tillmann, P., Tzortzopolous, P., Sapountzis, S., Formoso, C. \& Kagioglou, M., A case study on benefits realisation and its contributions for achieving project outcomes. Proceedings of the 20th IGLC, San Diego: USA, 2012.

[5] May, D., Sapountzis, S., Yates, K., Kagioglou, M. \& Aouad, G., Realising benefits in primary healthcare infrastructures. Facilities, 27(3/4), pp. 74-87, 2009. DOI: 10.1108/02632770910933116.

[6] State Services Commission, Gateway Review Process Best Practice - Gateway to Success (Vol. 0-5). Wellington: New Zealand Government, 2010 (Vol 2), 2013 (Vol. $0-1,3-5)$.

[7] NZTA, Economic Evaluation Manual, Wellington: New Zealand, 2013.

[8] NZTA, Assessment Framework for 2015-18 NLTP, Wellington: New Zealand, 2015.

[9] Resource Management Act, Pub. L. No. 1991 No 69, Wellington: New Zealand, 1991.

[10] Oxford English Dictionary (online version), available at http://www.oed.com/, 2016 (accessed 10 June 2014).

[11] Blom, C. \& Guthrie, P., Infrastructure Outcomes: What New Project Operational Expenditure Reveals as Missing. Proceedings of the Institution of Civil Engineers Municipal Engineer, 2016, available at http://www.icevirtuallibrary.com/doi/abs/10. 1680/jmuen.16.00025.

[12] Flyvbjerg, B., Skamris Holm, M. \& Buhl, S., How common and how large are cost overruns in transport infrastructure projects? Transport Reviews, 23(1), pp. 71-88, 2003. DOI: $10.1080 / 01441640309904$.

[13] Quinet, E., Cost-benefit indicators and transport programming. Fiscal Studies, 32(1), pp. 145-175, 2011. DOI: 10.1111/j.1475-5890.2011.00130.x.

[14] Thiry, M. \& Deguire, M., Recent developments in project-based organisations. International Journal of Project Management, 25(7), pp. 649-658, 2007. DOI: 10.1016/j. ijproman.2007.02.001.

[15] Lenfle, S. \& Loch, C., Has Megaproject Management Lost Its Way? Lessons from History, 2015.

[16] Auckland Council, The Auckland Plan, Auckland: New Zealand, 2012.

[17] Auckland Transport, Asset Management Plan 2015-2018, Auckland: New Zealand, 2015.

[18] Auckland Transport, Auckland Regional Land Transport Plan 2015-2025, Auckland: New Zealand, 2015.

[19] Auckland Transport, Regional Public Transport Plan, Auckland: New Zealand, 2015.

[20] Auckland Transport, Parking Strategy, Auckland: New Zealand, 2015.

[21] Auckland Transport, Statement of Intent 2014-2017, Auckland: New Zealand, 2014.

[22] Auckland Transport, Statement of Intent 2015/16- 2018/19, Auckland: New Zealand, 2014.

[23] Mitchell, R., Agle, B. \& Wood, D., Toward a theory of stakeholder identification and salience: Defining the principle of who and what really counts. Academy of Management Review, 22(4), pp. 853-886, 1997. DOI: 10.5465/AMR.1997.9711022105.

[24] Nadler, D. \& Tushman, M., A model for diagnosing organizational behavior. Organizational Dynamics, 9(2), pp. 35-51, 1980. DOI: 10.1016/0090-2616(80)90039-X.

[25] Grant, R., Butler, B., Hung, H. \& Orr, S., Contemporary Strategic Management: An Australasian Perspective. Australia: John Wiley \& Sons Australia Ltd, 2011.

[26] Carroll, L., Alice's Adventures in Wonderland and Through the Looking-Glass. London: J M Dent \& Sons Ltd, 1954. 
[27] Damart, S. \& Roy, B., The uses of cost-benefit analysis in public transportation decision-making in France. Transport Policy, 16(4), pp. 200-212, 2009. DOI: 10.1016/j. tranpol.2009.06.002.

[28] OMEGA Centre., Lessons for Decision-Makers: An Analysis of Selected International Large-scale Transport Infrastructure Projects Mega Projects, (Vol. Executive Summary). London: Bartlett School of Planning, University College London, pp. 52, 2012.

[29] Doz, Y. \& Kosonen, M., Governments for the Future: Building the Strategic and Agile State, Helsinki: Sweden, 2014.

[30] Blom, C. \& Guthrie, P., Surveying customer perceptions of road infrastructure comfort. Journal of Infrastructure Asset Management, 2(1), 2015. DOI: 10.1680/jinam.15.00007.

[31] Auckland Transport, Business Case for Construction: C. 100300 AMETI Package 1 Panmure Phase 1: To Proceed from Design to Construction, 2013.

[32] Ackoff, R., Towards a system of systems concepts. Management Science, 17(11), pp. 661-671, 1971. DOI: 10.1287/mnsc.17.11.661.

[33] Newig, J., Günther, D. \& Pahl-Wostl, C., Synapses in the Network: Learning in Governance Networks in the Context of Environmental Management. Ecology \& Society, 15(4), pp. 1-16, 2010.

[34] Box, R., Running government like a business implications for public administration theory and practice. The American Review of Public Administration, 29(1), pp. 19-43, 1999. DOI: $10.1177 / 02750749922064256$.

[35] Metcalfe, L., Public management: from imitation to innovation. Australian Journal of Public Administration, 52(3), pp. 292-304, 1993. DOI: 10.1111/j.1467-8500.1993. tb00281.x.

[36] Zimmerman, R. \& Sparrow, R., Workshop on Integrated Research for Civil Infrastructure, 1997.

[37] Senge, P., The Fifth Discipline: The Art and Practice of the Learning Organization (Second ed.). New York: Currency, 2006.

[38] Alvarez-Rosete, A., Hawkins, B. \& Parkhurst, J., Health System Stewardship and Evidence Informed Health Policy. London: GRIP-Health Programme, London School of Hygiene and Tropical Medicine, 2013.

[39] Hallsworth, M., How Complexity Economics Can Improve Government: Rethinking Policy Actors, Institutions and Structures. Complex new world: translating new economic thinking into public policy, IPPR (Institute for Public Policy Research): London, pp. 39-49, 2012.

[40] Snowden, D., Complex acts of knowing: Paradox and descriptive self-awareness. Bulletin of the American Society for Information Science and Technology, 29(4), pp. 23-28, 2003. DOI: 10.1002/bult.284. 